\title{
Use of Impact Fees To Incentivize Low-Impact Development and Promote Compact Growth
}

\author{
Zhongming Lu †, Douglas Noonan $\ddagger$, John Crittenden *†, Hyunju Jeong $\dagger$, and Dali Wang // \\ † Brook Byers Institute of Sustainable Systems, School of Civil and Environmental Engineering, \\ Georgia Institute of Technology, Atlanta, Georgia 30332, United States \\ ‡ School of Public and Environmental Affairs, Indiana University Public Policy Institute, \\ Indianapolis, Indiana 46202, United States \\ // Environmental Sciences Division \& Climate Change Sciences Institute, Oak Ridge National \\ Laboratory, Oak Ridge, Tennessee 37831, United States \\ *Phone: 01-404-894-5676. E-mail: john.crittenden@ce.gatech.edu
}

Author's Accepted Manuscript of the final version, published at:

Environ. Sci. Technol., 2013, 47 (19), pp 10744-10752. DOI: 10.1021/es304924w

\begin{abstract}
Low-impact development (LID) is an innovative stormwater management strategy that restores the predevelopment hydrology to prevent increased stormwater runoff from land development. Integrating LID into residential subdivisions and increasing population density by building more compact living spaces (e.g., apartment homes) can result in a more sustainable city by reducing stormwater runoff, saving infrastructural cost, increasing the number of affordable homes, and supporting public transportation. We develop an agent-based model (ABM) that describes the interactions between several decision-makers (i.e., local government, a developer, and homebuyers) and fiscal drivers (e.g., property taxes, impact fees). The model simulates the development of nine square miles of greenfield land. A more sustainable development (MSD) scenario introduces an impact fee that developers must pay if they choose not to use LID to build houses or apartment homes. Model simulations show homeowners selecting apartment homes $60 \%$ or $35 \%$ of the time after 30 years of development in MSD or business as usual (BAU) scenarios, respectively. The increased adoption of apartment homes results from the lower cost of using LID and improved quality of life for apartment homes relative to singlefamily homes. The MSD scenario generates more tax revenue and water savings than does BAU. A timedependent global sensitivity analysis quantifies the importance of socioeconomic variables on the adoption rate of apartment homes. The top influential factors are the annual pay rates (or capital recovery factor) for single-family houses and apartment homes. The ABM can be used by city managers and policymakers for scenario exploration in accordance with local conditions to evaluate the effectiveness of impact fees and other policies in promoting LID and compact growth. (Model 1)
\end{abstract}




\section{Introduction}

Low-impact development (LID) is a more sustainable solution for stormwater management that seeks to maintain the natural hydrologic characteristics of the site.(1) LID differs from conventional stormwater management (CSM), which uses drainage systems and detention tanks, as it includes the following infrastructures: (1) porous pavement, (2) creation of more open space (preserved native vegetation), (3) rainwater harvesting, (4) green roofs, (5) blue belts (retention ponds and infiltration basins), (6) reduced hardscape, and (7) grassy swales and wetlands for treating stormwater.(1, 2) In this study, we employ all of the above options except green roofs for stormwater management. The green space created by LID has additional benefits, such as reduced heat effects and improved air quality, recreational opportunities, and other amenities.(3) Presently, the U.S. EPA recommends the application of LID in coordination with smart growth principles to limit the conversion of land cover and preserve open space.(4) Based on the data for Atlanta, an apartment home and a single family house require 79 and 91 gallons of water per capita a day,(5) 12.6 and $28.3 \mathrm{kWh}$ of energy per capita a day,(6) and 200 and 1,350 square feet of land for housing, respectively. Also apartments provide higher passenger volume that makes public transportation more cost-effective and contributes to its walkability, which can reduce traffic.(7) If LID can effectively increase the adoption of apartment homes, the development will be more sustainable than a conventional, sprawling pattern.

Understanding the interdependency of infrastructure improvement and land development is difficult because dynamic urban systems are complex.(8) Analysis of highly complex emergent growth patterns using statistical methodologies requires large amounts of data and observations. However, few realworld examples of LID exist, and policies for LID have not been implemented for a long period of time.(9) As a result, agent-based models (ABM) that can account for heterogeneous and adaptive behaviors, information asymmetry, and uncertainty have been widely applied in artificial market simulations for complex adaptive systems such as housing markets, land use, and others.(10-13) There are many limitations for using the ABM to predict human behavior. First, we need to select the appropriate utility functions or fuzzy rules that describe the agents' behavior.(14) Second, the ABM is always a simplification of the potential interactions that occur in real world. $(15,16)$ Third, model parametrization and validation is a challenge because we do not have the data on the adoption rate to compare to our predictions.

Previous LID studies focused mainly on stormwater runoff control efficacy,(17-19) environmental improvement, $(20)$ and economic advantages $(3,21)$ at the individual subdivision level. The feasibility of implementing LID to increase apartment home adoption (AHA) has not been investigated. Meanwhile, although LID has been shown to be an effective strategy, it has not been widely adopted, due to a lack of effective regulations and incentives that can drive the adoption of LID. $(22,23)$ In this study, we propose the imposition of an impact fee to incentivize the adoption of LID techniques. If developers build projects that do not use LID practices, then they must pay impact fees such that allow local government to fully employ LID for public space and residential properties to control stormwater. The goal of this study is to understand the effect of tax investment and impact fees on the adoption of LID and apartment homes (as opposed to detached single family homes). 
In this study, we develop an ABM that predicts the development of greenfield land for residential purposes. In particular, the ABM predicts the adoption rate of LID and apartment homes in response to fees that are assessed if LID is not adopted. The ABM simulates several decision-making processes, including individuals' house choices, the developer's investment choices, the government's infrastructure improvements, and drivers such as tax revenue and impact fees. The model simulates the development pattern of ten-acre "subdivision" increments. Homebuyers choose to purchase singlefamily houses or apartment homes. Each subdivision will receive CSM or LID to capture the first 1.5 in. of rainwater per 24-h period and transportation improvements to reduce traffic cost. Model parameters are obtained from the existing literature and include consumer preferences, cost, and national market statistics. The model is validated by comparing the predicted house price with the existing hedonic price analysis results. In a given model run, agents act and interact according to the rules, resulting in the emergent adoption curve of the two residence options and a land use pattern. We develop two scenarios: business as usual (BAU) where no impact fee is imposed and more sustainable development (MSD) scenarios where the impact fee is proposed to incentivize the adoption of LID and apartments. For BAU, CSM is used. For MSD, the developer decides whether to build LID or pay as fee, and local government builds LID for public space and private properties using the tax and fee receipts. We examine whether the AHA is greater for MSD than BAU. To evaluate the sustainability of development patterns, we should consider the individual and interactive impacts of infrastructure systems (e.g., transportation, water, energy, and buildings).(24) In this study, we did not perform a detailed design of infrastructure systems; consequently, we could only compare sustainability performance based on land conservation, property tax revenue, transportation improvement, and water savings. Finally, we apply a time-dependent global sensitivity analysis to estimate the influence of socioeconomic factors that determine the effect of impact fees and LID on AHA.

\section{Materials and Methods}

To introduce the features of the ABM that incorporate the agents' behaviors (e.g., finding a house, improving infrastructure, and building properties) and interactions (e.g., tax payment, impact fees, house sale), we include the following sections.

Study Area and Agent Types

The study area is greenfield land next to an urban area. The nine square miles are divided into $24 \times 24$ grid cells that contain ten-acre plots. A basic water supply, a sanitation sewer network, a stormwater drainage system, and roads are prerequisites of the development, and the local government uses funding from the federal and state governments to build these infrastructures. (The additional infrastructure that is needed to control $1.5 \mathrm{in}$. during a $24 \mathrm{~h}$ period is either by LID or detention tanks. This infrastructure has to be paid for by homeowners, local government, and/or developer.) We do not consider the impact of business growth on residential development; we assume all residences have equal access to businesses. Two residential subdivision types are developed: (1) single-family homes comprising a lower-density subdivision and (2) apartment buildings comprising a higher-density subdivision (Figure 1). 
The model simulates the interactions of three agents: one agent representing government, one agent representing the developer, and agents representing homebuyers. The government provides infrastructure services and improvements. The developer converts the undeveloped land into residential subdivisions to satisfy housing demand and sells the properties to homebuyers. The homebuyer's objective is to purchase a residence. Bounded rationality is used to simulate home selection, which assumes limited information is available and an individual cannot consider every possibility.(25) The state variables of agents are summarized more thoroughly in the Supporting Information (SI).

Infrastructure Improvement and Impact Fee

In this study, stormwater management and transportation improvements are considered. Storm water management aims to capture the first $1.5 \mathrm{in}$. of rainwater per 24-h period over each subdivision. CSM and LID are alternative stormwater management strategies that are used for BAU and MSD, respectively. CSM incorporates underground detention tanks into the storm sewer system and provides temporary storage of stormwater, which is slowly released into the storm sewer. The detention tanks reduce the peak discharge flow and reduce the mass loading of pollutants because some pollutants are removed by sedimentation.(26) In contrast, LID harvests rainwater to control the $1.5 \mathrm{in}$. of rainwater, and households use most of the rainfall for nonpotable water (irrigation and toilet flushing) uses. Based on the annual 47-in. rainfall (the average for 2005 through 2011) in metro Atlanta, the harvested rainwater provides 53 gallons of water per capita per day for single-family houses and 11 gallons of water per capita per day for apartment homes (details of rainwater harvesting computation can be found in the SI). This harvested rainwater reduces the amount of water that needs to be supplied from a central water treatment facility ( $58 \%$ for single-family houses and $20 \%$ for apartment homes). The harvested rainwater except for that used irrigation ends in the sanitation sewer (40 gallons of water per capita per day for single-family houses and 5.5 gallons of water per capita per day for apartment homes).

LID in public spaces is financed by the local government. Public LID is an improvement of green space, which includes rain gardens, tree filter boxes, vegetated infiltration basins, and native plants. Public LID reduces the fiscal burden for local government and homeowners (who pay property taxes) because more costly CSM is not needed (see SI Figure S1 for a comparison of the costs). Homeowner LID is a private property improvement, which includes permeable surfaces, rain barrels, and roadside swales (see SI Storm Water Management Techniques). If the developer chooses not to use homeowner LID, then the government has to pay the cost for homeowner LID so that the LID can capture the $1.5 \mathrm{in}$. of rainwater. Hence, local government charges the developer impact fees that can cover most of the cost for homeowner LID. The impact fees here are set to $\$ 13,000$ per single-family house and $\$ 1,500$ per apartment homes (see SI Impact Fee).

Transportation improvement is provided by the government to guarantee traffic mobility between the new developed area and the rest of the city, rather than the improvement of local transportation within the single-family or apartment home subdivisions. Transportation improvement refers to the public transportation investment. The direct benefits to homeowners include shorter travel times, increased mobility, and financial savings. We define the term "traffic cost savings" to encompass these benefits. A 
traffic cost savings of $\$ 1,000$ means that a household can reduce its yearly transportation expenses by $\$ 1,000$. The traffic cost savings at time $t$ equals the investment in transportation facilities by the government per housing unit at $t$ multiplied by the return in transportation cost savings for every dollar plus the discounted saving at time $t-1$. The return in transportation cost savings for every dollar is 10 cents for a single-family house and 30 cents for an apartment home.(7) The goal of transportation improvement is to save households $40 \%$ of traffic costs. Transportation savings improve the quality of life for apartment homes and single-family houses.

\section{Process Overview and Scheduling}

The overall goal driving land development and the interactions among agents is meeting the increasing demand for housing (see SI Design Concepts). The state and macroeconomic variables are listed in Table S1. One thousand prospective homebuyers are assumed to enter the housing market every year. The agent-based housing market model proceeds in annual time steps, and the simulation runs for 30 years. In the initial step $(t=0)$, the developer builds 616 single-family houses and 540 apartment homes (see SI Model Initialization), which corresponds to 16 subdivisions. Homebuyers search for ideal properties to purchase and make the deals with the developer. This process generates initial residents, demand, and prices. In the next time step, the five modules of the model are run as described in the following order (Figure 2, see SI Model Details).

\section{Collection of Taxes To Support Infrastructure Improvement}

First, we discuss the collection of taxes for stormwater management of apartment homes. The government's budget for apartment homes' stormwater management is calculated at the start of the first year $(t=1)$ as the sum of the cost of installing the CSM or public LID for apartment homes. In the first year, the government borrows money if property taxes (tax rate $=1 \%$ of the assessed home value) paid by apartment homeowners are insufficient to complete installation of the CSM or public LID. In the following years, the government does not borrow money for new CSM or public LID, and only tax revenues can fund new CSM or public LID. However, the property tax rate for stormwater management cannot exceed $1 \%$ of the apartment home value unless the property taxes cannot cover the maintenance and debt service cost. In such cases, the tax rate can exceed $1 \%$. Also the tax rate for stormwater management can decrease when property taxes at the rate of $1 \%$ exceed the cost for apartment homes' stormwater management. (This ABM does not include any tax revenues for other important services like schools or public safety. If they were included, the tax savings from stormwater management could be used to improve these services.) The same procedure applies in single-family houses for their tax rate for stormwater management. Transportation improvements starts at the beginning of the sixth year $(t=6)$ with a fixed tax rate of $1 \%$.

Infrastructure Improvement: Storm Water Management and Transportation Improvement

Tax revenues collected from completed subdivisions are used by subdivisions of the same type for maintenance and improvement. Each subdivision, including the subdivisions that will be built in the current time period, receives the same funding from property taxes paid by current homeowners. If one subdivision needs less than it receives to fulfill improvement targets, the surplus will be shared among 
the other subdivisions. The amount of improved open space and traffic cost savings are updated after each yearly investment.

Developer Decision Making: Building Apartments and Houses To Meet the Current Year's Demand

The developer builds new apartments and single-family houses to satisfy the demand for the current year. The demand for new houses (or the number of new homes that are built) is the difference between the number of bids and the inventory. For BAU, CSM is used. For MSD, the developer decides whether to build LID or pay as fee. The impact fee is $\$ 13,000$ per single-family house and $\$ 1,500$ per apartment home. In contrast, the cost that the developer has to pay to implement LID as compared with traditional construction is $\$ 5,077$ per single-family house and $\$ 715$ per apartment home (see SI Figure S1). (Also properties with LID will command a higher price as compared with properties that use CSM.) Consequently, the developer will implement LID. The asking price and the minimum annual payment for apartment homes and single-family houses are given in eqs 1 and 2 . The developer adds the impact fee instead of the incremental cost of installing LID, because the developer has a monopoly in this case and the power to pick the home price

$$
P=\left(C_{h}+C_{i n}\right) \times(I+\eta)+I F
$$

where $P$ is the floor price to sell, or asking price; $C_{h}$ is the building construction cost; $C_{i n}$ is the subdivision infrastructure cost (e.g., cost per mile of roads approaching subdivisions, subdivision grading cost, cost of connecting subdivisions to water, sanitation, and storm networks); $\eta$ is the ratio of soft cost (e.g., financing cost, permit fees) and minimal profit to hard cost $\left(C_{h}+C_{i n}\right)$; and IF is the impact fee

$$
A P_{k}=P_{k} \times P R
$$

where $A P_{k}$ is the annual payment (or the incoming cash flow from an investor's perspective) of house $k$; $P_{k}$ is the floor price of house $k$; and $P R$ is the annual payment rate of house $k$ (i.e., the ratio of annual mortgage interest and principal to property value). The $P R$ of apartment homes $\left(P R_{a p}\right)$ and $P R$ of singlefamily houses $\left(P R_{s f}\right)$ is $8 \%$ and $4 \%$, respectively. Both percentages are consistent with typical values (see SI Payment Rate).

House Search: Finding a House

Each of the 1,000 homebuyers examines ten homes for potential purchase. If the willingness to pay (WTP, eq 3$)(27,28)$ for a particular house exceeds minimum annual payment, the homebuyer puts that house into their choice set of potential homes for purchase. After reviewing 10 homes, the homebuyer bids on the best option out of the choice set. The choice algorithm of how homebuyers select one out of the alternatives for bidding is discussed in the $\mathrm{SI}$

$$
W T P_{i, j}=\left(I_{i} \times E-T C_{i}-\operatorname{Tax}_{j}-M_{j}\right) x \frac{U_{i, j}^{2}}{U_{i, j}^{2}+B_{i}^{2}}
$$

where $W T P_{i, j}$ is the WTP of homebuyer $i$ for a house in subdivision $j ; I_{i}$ is the annual income of homebuyer $i$; $E$ is expenditure as a proportion of income; $T C_{i}$ is the traffic cost of homebuyer $i$; $\operatorname{Tax}_{j}$ is 
the expected property tax, which is equal to $40 \%$ of the asking price multiplied by the tax rate; $M_{j}$ is the maintenance fee per unit in subdivision $j ; U_{i, j}$ is the unitless utility of homebuyer $i$ in a house in the subdivision $j$ (eq 4); and $B i$ is the unitless utility of nonhousing expenditure of homebuyer $i$

$$
U_{i, j}=\gamma_{i, L S} \times \log \left(L S_{j}\right)+\gamma_{i, H S} \times \log \left(H S_{j}\right)++\gamma_{i, O S} \times \log \left(O S_{j}\right)+\gamma_{i, T C S} \times \log \left(T C S_{j}\right)
$$

where $L S_{j}$ is the lot size (ft2); $H S_{j}$ is the house size (ft2); $O S_{j}$ is improved open space (ft2); $T C S_{j}$ is the traffic cost savings $(\$ / y r)$; and $\gamma$ weights the influence of these attributes in the homebuyer's personal utility perception, which is derived from individual preferences.

Preference for open space is defined by people's marginal WTP for additional open space. Homebuyers are willing to pay more for open space featured by LID technologies.(29) More importantly, the value of open space is higher in compact subdivisions than traditional ones.(29-31) We model the WTP for a house with $100 \%$ more open space as rising from $0.45 \%$ (of home value) for either residence type under CSM construction to $0.54 \%$ for single-family houses and to $1.44 \%$ for apartment homes built with LID techniques. Preferences for lot size, house size, and traffic cost savings are discussed in the SI.

House Sale Process

The developer sells properties to the homebuyers who offer the highest WTP for each property, which must exceed the minimal annual payment. The process results in the appreciation of prices that is used to update property values of the sold houses.

\section{Economic-Environmental Impacts}

This study examines the economic-environmental impacts - tax revenues and water savings-associated with different land use patterns and infrastructures. The tax revenues that government can use for other purposes (e.g., schools and public safety) are equal to the property tax minus the yearly budget for stormwater management and transportation improvement. Gross tax revenues are proportional to aggregate property values, which is also a proxy for residents' economic welfare. Water savings are due to the reduced water demand from apartments and increased water supply from rainwater harvesting.

Time-Dependent Global Sensitivity Analysis

A time-dependent global sensitivity analysis (GSA) was conducted using SimLab (http://simlab.jrc.ec.europa.eu/) to understand the effect of socioeconomic factors (see SI Table S4) in shaping the MSD scenario. The analysis randomly generates 1,408 Monte Carlo (MC) input samples given the $\pm 5 \%$ range for use in examining the individual and interactive impact of factors on the AHA. The experimental procedure follows that in a study by Ligmann-Zielinska and Sun (see SI Time-Based Global Sensitivity Analysis).(32)

\section{Results and Discussion}

Model Validation 
In this study, we use a pattern-oriented calibration and validation process.(33) The pattern-oriented model design assigns values to parameters on the basis of observed patterns in the agents. The emergent properties are compared with the observations to validate the ABM. We collect the data for the parameters from the existing literature on preferences, construction cost, and market statistics (see Table S1), and then we compare the emergent housing prices from the market trading with existing hedonic studies on house price and the effect of LID to validate the model. We discuss the consistency of the observed adoptions with previous findings in the next section.

House prices emerge from the interactions among homebuyers, the developer, and local government through the housing market. In the BAU scenario, the price in the starting year $(\mathrm{t}=0)$ is approximately $\$ 348,156$ per single-family house and $\$ 149,664$ per apartment home. These starting values are close to the hedonic house prices estimated using a tool developed by the National Association of Home Builders $(\$ 336,270$ per single-family house and $\$ 144,262$ per apartment home) (see the SI discussion on House Price). The house price increases because of the promotion of stormwater management and transportation improvements. For example, by the fifth year, the single-family house value rises by 4.56\% with CSM and $4.83 \%$ with LID (SI Figure S2a), whereas the apartment home value rises by $6.07 \%$ with CSM and $14.60 \%$ with LID (SI Figure S2b). The appreciation of house and apartment prices that results from increased open space and stormwater management is consistent with empirical studies, which have found comparable values ranging from $2.7 \%$ to $15 \%$.(34-38) The consistency with values of house prices and appreciation values from the literature indicates that the ABM structure and parameters are reasonable.

\section{Adoption of Apartment Homes}

The major goal of this study is to understand the effect of impact fees on the adoption of LID and on residential land use patterns. The incentives resulting from infrastructure improvements (e.g., increased open space, traffic cost savings) can affect homebuyers' choices. In the BAU scenario, single-family subdivisions are the dominant design type. After 30 years, $64.8 \%$ and $35.2 \%$ of built properties are single-family houses and apartment homes (Figure 3a), respectively. CSM is not particularly valuable to homebuyers choosing apartments or to the developer building apartments. Even when transportation improvements are introduced later, apartments remain less attractive to homebuyers and the developer than single-family houses. The BAU scenario captures the reality that the conventional design and infrastructure improvement make single-family houses more popular (see SI Figure S3a).

In the MSD scenario, we introduce impact fees to incentivize the adoption of LID. Model simulation shows a transition from lower- to higher-density land use. After 30 years, $58.7 \%$ of the built properties are apartment homes (Figure $3 \mathrm{~b}$ ). The developed area in the MSD scenario is $25 \%$ smaller than that in the BAU scenario (see SI Figure S3b). The more expensive apartments in MSD relative to BAU do not adversely affect the choice of living in an apartment because buyers' WTP is increased as a result of more valuable open space using LID and reduced transportation costs. The predominance of inexpensive apartment homes (relative to single-family houses) also improves overall housing affordability. As a result, the model predicts that the total number of households in the development increases by $4 \%$ more in the MSD scenario than in the BAU scenario. 
In the following paragraphs, we examine how impact fees for LID result in higher AHA in MSD. First, we begin with the impact of the LID fee. Figure $3 c$ shows the case where the LID fee is collected but LID is not implemented. Accordingly Figure $3 c$ displays the impact of the fee collection but without the utility improvement that occurs with the implementation of LID. As shown in Figure $3 c$ as compared to Figure $3 a$, there is a slight increase in AHA. This observation is consistent with the finding that the impact fee to fund CSM does not significantly affect the construction of single-family houses.(39) (CSM is an infrastructure that homeowners cannot see and does not provide the same utility as LID.) Impact fees make single-family houses relatively more expensive than apartment homes, which results in a slight increase in the AHA. But the increase in prices does not improve the quality of life (e.g., green space and traffic cost savings) for apartment owners since LID is not employed. Consequently, the AHA is not substantially increased.

Determining who pays for homeowner LID (i.e., for private residential property) dictates how much money the local government needs for LID. We look at the scenario where the local government pays for both homeowner and public LID using tax revenues and compare it to the scenario where the developer pays for homeowner LID in MSD. Figure 3d displays the case where the local government pays for homeowner and public LID. Comparing Figure $3 d$ to Figure $3 b$ shows a higher AHA when the developer pays for homeowner LID in MSD. The increase in AHA is because using LID increases the quality of life of apartment owners more than that of single-family houses and the government has more money for public LID and transportation improvement by imposing impact fees for homeowner LID on the developer.

Factors including buyers' WTP for LID, tax rates, and amount of property tax revenues are the major drivers of the shift from a single-family house-dominated market to an apartment home-dominated market in the development. As shown in Figure 3b, the AHA is less than the single-family house adoption rate for years 1 to 8 . This trend can be understood by examining the economic flows that are used to pay for public LID. During these years the tax revenue is insufficient to pay for public LID. As a result, the quality of life for apartment owners does not increase as much as it does for later years, when there are sufficient funds to finance public LID. In addition, taxes are higher during those years and apartment buyers' WTP is reduced. After year 8 , there is sufficient tax revenue for public LID and the tax rate for apartment owners is smaller. This, in turn, increases AHA, because public and homeowner LID will be fully deployed and this increases the apartment owners' quality of life. In addition, taxes are lower in subsequent years and apartment buyers' WTP is increased. Importantly, we need to mention that transportation improvement begins in year 6 , and this also improves the quality of life.

Another factor contributing to the shift is that fees must be paid by the developer if he does not implement homeowner LID. It turns out that it is more profitable for the developer to voluntarily implement homeowner LID than pay the fees because adoption costs are lower than nonadoption impacts on government infrastructure costs and the developer would charge the homeowner the fee even though the cost of implementation is less than the fee (see eq 1 ). The cost for homeowner LID for single-family houses is more than for apartment homes. Also, the government's cost for public LID is less for apartment homes, and apartment owners provide more tax revenues than single-family homeowners. At year 8, single-family houses still face a shortfall of tax revenues to pay for public LID. 
Consequently, public LID is implemented later, and the tax rate remains higher until the funds for public LID development are collected. On the other hand, apartment homeowners provide enough tax revenue to pay for public LID, it is immediately implemented, and the tax rate is lower for future homeowners. As a result, the quality of life and WTP increases faster for apartment homeowners than that of singlefamily houses. Therefore, many buyers are more willing to choose apartment homes than single-family houses.

Economic-Environmental Impacts

Property Tax Revenues

Given a fixed rate at $1 \%$ for stormwater management before year 6 and $2 \%$ for stormwater management and transportation improvement after year 6 , the accumulated tax revenues minus the accumulated cost for stormwater management and transportation improvement are shown in Figure 4a. The net tax revenues in MSD are 55.4\% higher than in BAU for 9 mi2 after 30 years. More property tax revenues will allow for more improvements in infrastructure as schools, public safety, etc. Also the average traffic cost savings per household in MSD increases by $12 \%$ as compared with BAU after 30 years. Overall, we observe a more prosperous real estate market in the MSD scenario than in BAU, which is suggestive of the effectiveness of the LID and impact fee policy.

Rainwater Harvesting and Water Savings

The average water demand per capita per year is 31,310 gallons in BAU and 28,886 gallons in MSD. Meanwhile, rainwater runoff collected from rooftops, pervious landscape, and green space can supply part of local water demand. Water supply from a central water plant is reduced by $41.5 \%$ in MSD owing to the rainwater harvesting (Figure $4 \mathrm{~b}$ ). More importantly, the operation (and capital) cost for water supplied by the central water plant is expected to decrease in MSD because of the more compact land use and shorter transport distances within the developed area. However, rain data pertain to the example of Atlanta, and thus conclusions regarding rainwater harvesting cannot necessarily be generalized to all cities.

Time-Dependent Global Sensitivity Analysis

The sensitivity analysis shows the high-level interactions among inputs to the ABM (see SI Figure S5). The results of the GSA using Sobol's approach are discussed in detail in SI Table S7. The two most influential factors based on the mean first-order index are PRap and PRsf, which are related to the annual payment (eq 3). The pay rate affects the adoption rate because if the annual payment is smaller than the amount the buyer is willing to pay, then the homebuyer will consider purchasing this property. Results indicate the significant impact of financial market for real estate development on AHA.

With respect to the sensitivity of impact fees on AHA, we need to look at the incentive of impact fees as compared with the additional cost to the developer of using homeowner LID. In MSD, the government levies impact fees in the amount of $\$ 13,000$ per single-family house and $\$ 1,500$ per apartment home. The government could use these fees to mostly cover the cost of homeowner LID if the developer 
chooses to build properties without homeowner LID. In contrast to the impact fees, the additional cost to the developer of using homeowner LID rather than conventional construction is $\$ 5,077$ per singlefamily house and $\$ 715$ per apartment home. Therefore, the developer will implement homeowner LID, because this results in a lower net cost. From the time-dependent GSA, the selected value of impact fees does not exert a significant effect on AHA given $\pm 5 \%$ range. Cutting impact fees in half would still have no effect, because the effect on government costs from subsidizing homeowner LID when the developer declines to use LID at initial construction so greatly exceeds the incremental cost to the developer of initially adopting homeowner LID. However, if the impact fee is set low enough to erode the cost-savings to the developer from adopting homeowner LID and avoiding the fee, then AHA rates fall where the developer pays the impact fees and the government pays the retrofit cost for homeowner LID (close to Figure $3 \mathrm{~d}$ ) relative to the scenario where the developer adopts homeowner LID without paying the impact fees (Figure 3b). Overall, we can conclude that the AHA is sensitive to the magnitude of impact fees. An impact fee that can exceed the cost-savings to developer from adopting homeowner LID and avoiding the fee will induce homeowner LID adoption and high AHA rates, but sufficiently discounting the impact fee will lead to no homeowner LID adoption and lower AHA rates.

The time-dependent sensitivity analysis also provides insight into the time-based importance of input factors. As shown in Figure $S 6, P R_{a p}$ exerts less influence on the adoption of apartment homes over time, whereas the elasticity of WTP in terms of house size increasingly affects the adoption rate. By investigating the dynamics of influence, it is possible to investigate which policies will promote higher AHA at different times.

Overall, this study has developed an agent-based housing market model that incorporates our understanding of the interactions among fees to incentivize LID adoption, WTP for properties, and tax revenues for infrastructure improvement (e.g., rainwater harvesting, storm runoff control, traffic mobility). The ABM may be extended to the city level to examine the influence of the connections among infrastructure systems (e.g., transportation water and energy), economic flows, house and work location, and land use. The extended model may also be able to evaluate technical, economic, and political strategies for making urban systems more sustainable.

The real housing market is much more complex than that simulated with our $A B M$, because homebuyers' and the developer's decision making involves more issues than we chose to consider in this study. These issues, which we did not focus on as variables, also influence homebuyers' and the developer's decisions including the following: (1) school district quality, (2) crime rate, (3) social norms and status, (4) childcare availability, (5) land acquisition, (6) permit issuance, (7) project financing, (8) market competition between many development on a city wide basis, and (9) influence of other markets, for example, the financial or labor markets. In addition, future research could consider how homebuyers share their opinions with one another and how this influences their decisions.

The ABM that we have developed is a first step toward developing a useful model that policymakers can use. However, the future capability of $A B M$ can be greatly improved, because of tremendous increases in computation power,(40) greater availability of socioeconomic data,(41) and an increased understanding of human behavior $(42,43)$ including the actors that involved in (re)development (i.e., 
interactions between developers, homebuyers, government, etc.). We believe that improved ABM will allow us to predict the adoption of more sustainable approaches for urban (re)development in response to policy instruments.

\section{Supporting Information}

Information about agents, stormwater management, impact fees, design concepts, model details and initialization, simulation platform, model parameters that describe homebuyer's preference, pay rates, runoff calculation, rainwater harvesting, and sensitivity analysis method used here is provided. This material is available free of charge via the Internet at http://pubs.acs.org/doi/suppl/10.1021/es304924w/suppl_file/es304924w_si_001.pdf

The authors declare no competing financial interest.

\section{Acknowledgement}

Financial support from the National Science Foundation for Resilient and Sustainable Infrastructures (RESIN) is gratefully acknowledged. This work was also partially supported by Brook Byers Institute for Sustainable Systems, the Hightower Chair and Georgia Research Alliance. The authors wish to thank Kathryn Jonell, Arka Pandit, and Xuewei Yu, for help in revising the paper. Finally, we would like to thank all of the anonymous reviewers and their comments. 
Model 1

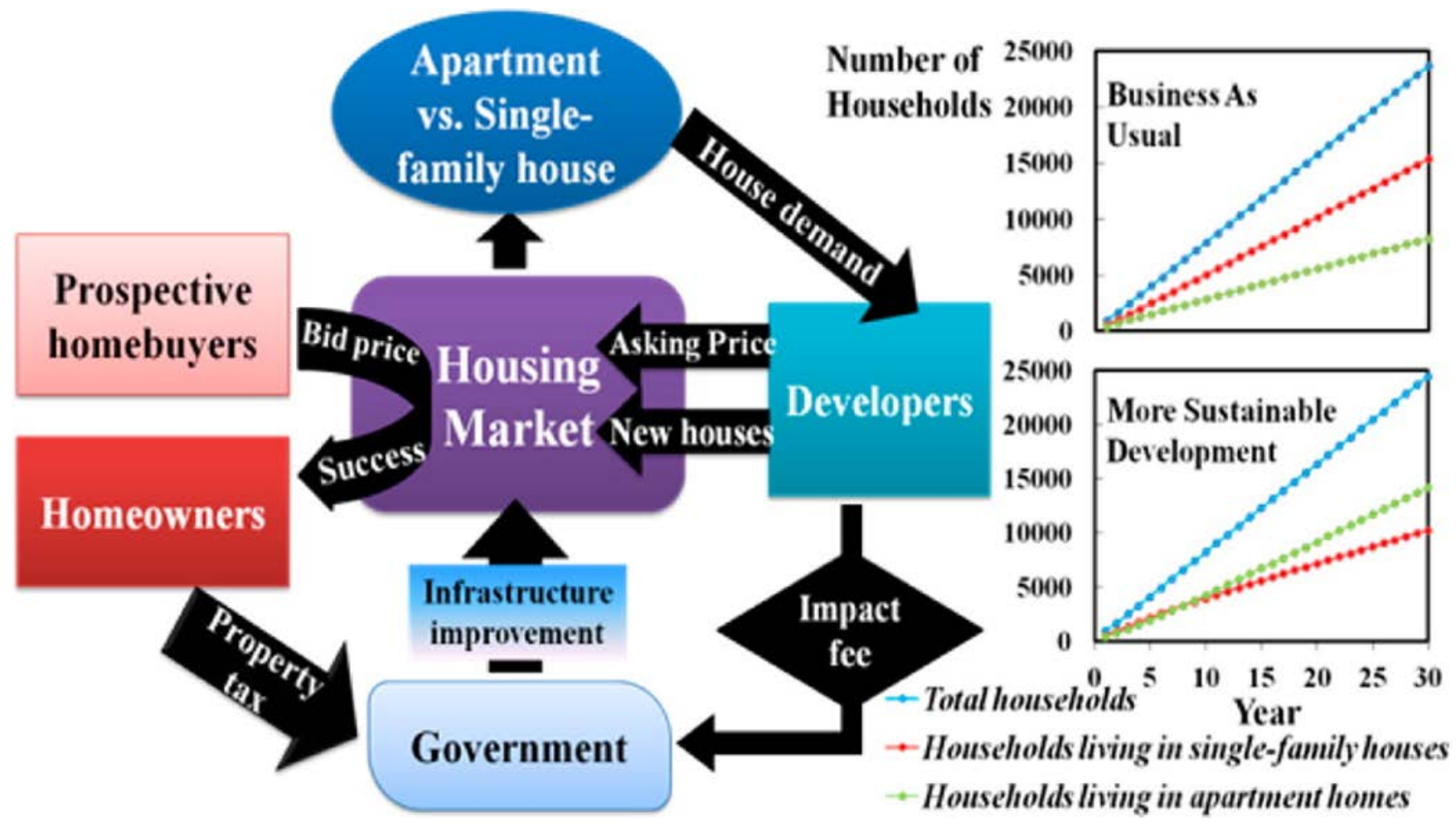


Figure 1. Figure 1. Residential subdivision design: single-family house representing low-density development (top) versus apartment home (bottom) representing high-density development.

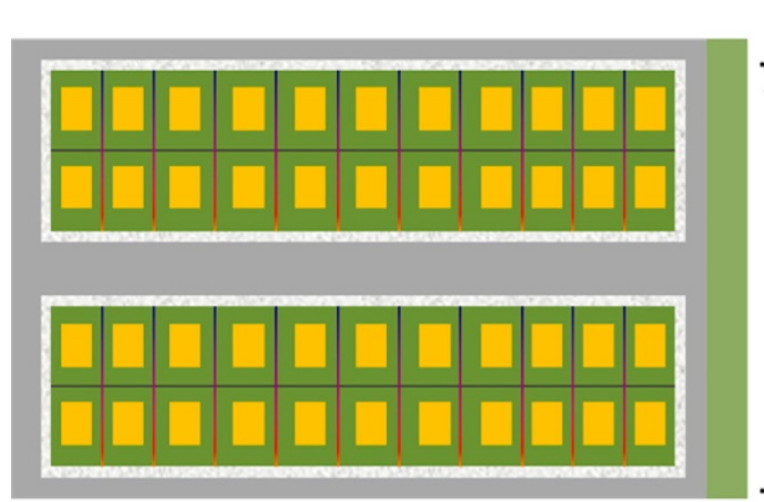

Single-family house

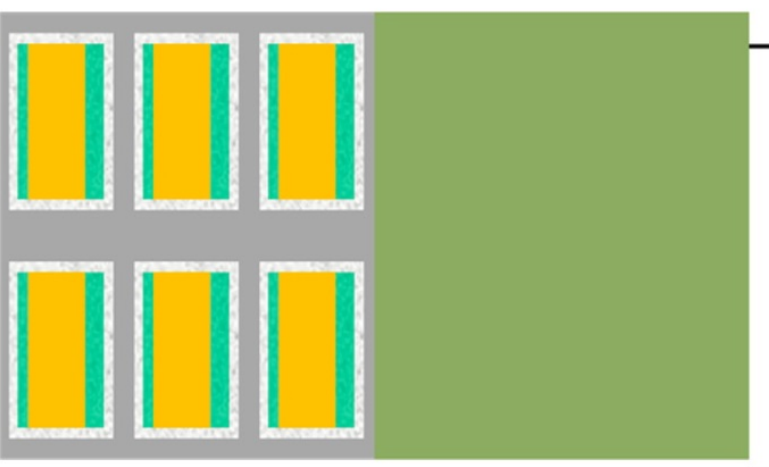

10 acre-size residential subdivision

$\begin{array}{cc}\text { Lot size } & 7,260 \mathrm{sq} \mathrm{ft} \\ \text { House size } & 2,688 \mathrm{sq} \mathrm{ft} \\ \text { Housing } \% & 73.5 \% \\ \text { Infrastructure } \% & 23.6 \% \\ \text { Public space } \% & 2.9 \% \\ \text { Dwelling unit } & 44 \\ \text { Population } & 110\end{array}$

Population density (person/acre) 11

\section{Apartment home}

10 acre-size residential subdivision

$\begin{array}{cc}\text { Lot size } & 1,200 \mathrm{sq} \mathrm{ft} \\ \text { House size } & 1,200 \mathrm{sq} \mathrm{ft} \\ \text { Housing\% } & 13.8 \% \\ \text { Infrastructure\% } & 22.9 \% \\ \text { Public space } \% & 63.3 \% \\ \text { Dwelling unit } & 270 \\ \text { Population } & 675 \\ \text { on density (person/acre) } & 67.5\end{array}$
House/
Building
Street
Open Space
Private Yard
Front and
Back yard 
Figure 2. Flowchart for the agent-based housing marketing simulation with infrastructure improvements occurs in the following order: 1) house search, 2) house sale, 3) house investment, 4) collection of taxes, and 5) infrastructure improvement (see Process Overview and Scheduling for the details).

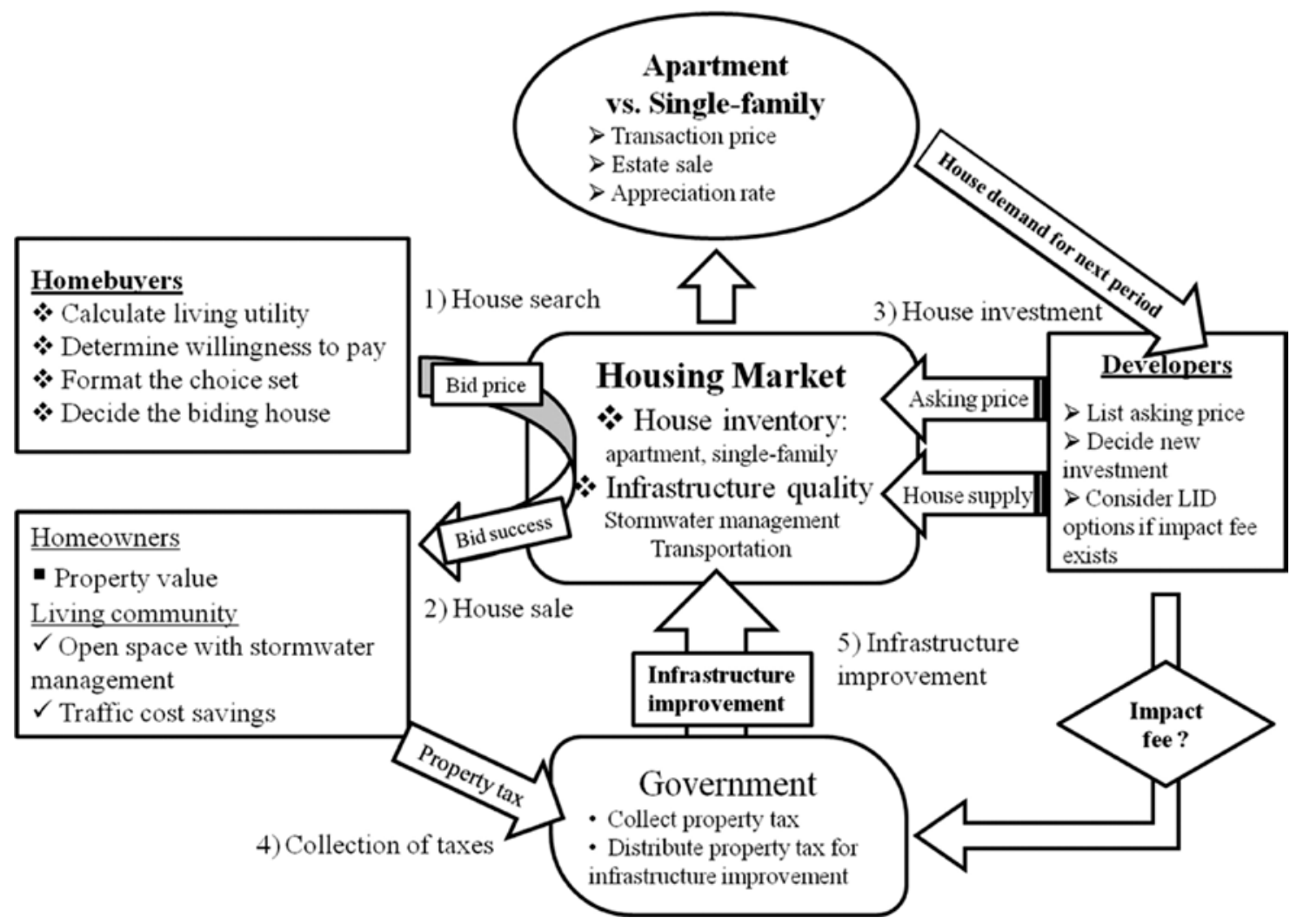


Figure 3. Household allocation between the two types of residential subdivisions: (a) business as usual (BAU); (b) more sustainable development (MSD): impact fees serve as an incentive for the developer to implement LID; (c) the developer builds properties conventionally and pays the impact fee designed to fund CSM; (d) the government pays for the costs of both homeowner and public LID.
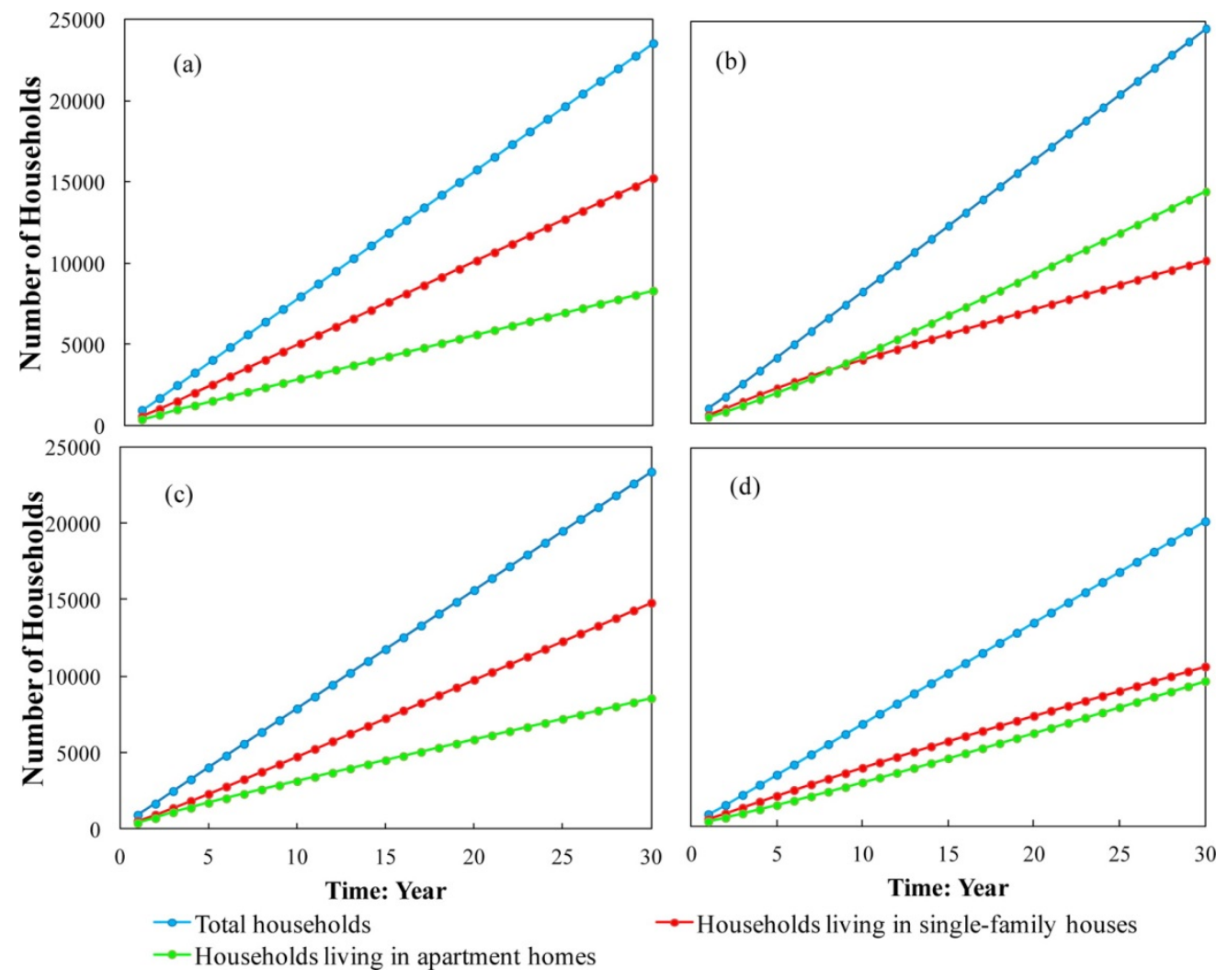

$\rightarrow$ Households living in single-family houses

$\rightarrow$ Households living in apartment homes 
Figure 4. Economic-environmental benefits in MSD and BAU: (a) the accumulated tax revenues minus the accumulated cost for stormwater management and transportation improvement given the predefined tax rate ; (b) the annual water demand and water supply from the water treatment plant for the developed area based on the water demand in metro Atlanta.
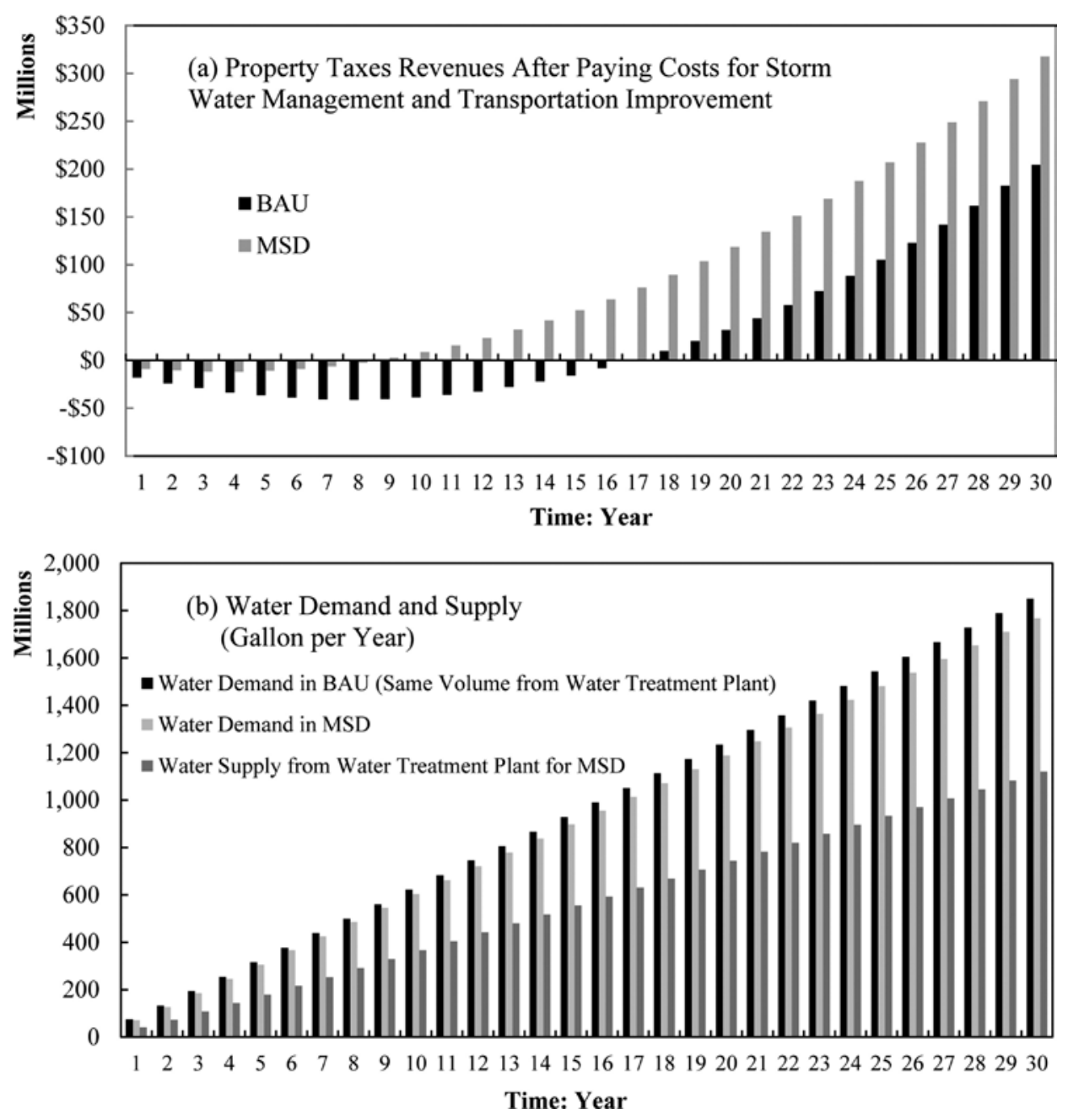


\section{References}

1. Coffman, L. Low-impact development: an integrated design approach; Department of Environmental Resource Programs and Planning Division: Largo, MD, 1999. http://water.epa.gov/polwaste/green/upload/lidnatl.pdf (accessed July 10, 2013).

2. Hinman, C. Low impact development, technical guidance manual for Puget Sound; Washington State University: 2005. http://www.psp.wa.gov/downloads/LID/LID_manual2005.pdf (accessed July 10, 2013).

3. The triple bottom line assessment of traditional and green infrastructure options for controlling CSO events in Philadelphia's watersheds; City of Philadelphia, 2009.

http://www.michigan.gov/documents/dnr/TBL.AssessmentGreenVsTraditionalStormwaterMgt_293337_ 7.pdf (accessed July 10, 2013).

4. EPA. Low impact development (LID) and other green design strategies. http://cfpub.epa.gov/npdes/stormwater/menuofbmps/index.cfm?action=factsheet_results\&view=speci fic\&bmp=124 (accessed July 10, 2013).

5. A review of water conservation planning for the Atlanta, Georgia Region; Pacific Institute for Studies in Development, Environment, and Security: Oakland, 2006. http://www.pacinst.org/reports/atlanta/atlanta_analysis.pdf (accessed July 10, 2013).

6. Household site end-use consumption in the South Region, totals and averages, 2009; Energy Information Adminstration, U.S., 2009. http://www.eia.gov/consumption/residential/data/2009/index.cfm?view=consumption (accessed July 10, 2013).

7. Litman, T. Evaluating public transit benefits and costs; Victoria Transport Policy Institute: 2012. http://www.vtpi.org/tranben.pdf (accessed July 10, 2013).

8. Miller, J. H.; Page, S. E. Complex Adaptive Systems: An Introduction to Computational Models of Social Life; Princeton University Press: 2007.

9. Andrea, B. Implementing low impact development in Pender County, North Carolina; Pender County Planning and Community Development: 2011.

http://www.nccoast.org/uploads/documents/About\%20us/Pelican\%20Awards/Implementing\%20LID\%2 0in\%20Pender\%20County.pdf (accessed July 10, 2013).

10. Xu, M.; Allenby, B.; Kim, J.; Kahhat, R.A dynamic agent-based analysis for the environmental impacts of conventional and novel book retailing Environ. Sci. Technol. 2009, 43 ( 8) 2851-2857

11. Schluter, M.; Pahl-Wostl, C.Mechanisms of resilience in common-pool resource management systems: an agent-based model of water use in a river basin Ecol. Soc. 2007, 12 (2) 23

12. Filatova, T.; Voinov, A.; Veen, A.Land market mechanisms for preservation of space for coastal ecosystems: An agent-based analysis Environ. Modell. Softw. 2011, 26 ( 2) 179-190 
13. Zhang, B.; Yu, Q. Q.; Bi, J.Policy design and performance of emissions trading markets: an adaptive agent-based analysis Environ. Sci. Technol. 2010, 44 (15) 5693- 5699

14. Parker, D. C.; Manson, S. M.; Janssen, M. A.; Hoffmann, M. J.; Deadman, P.Multi-agent systems for the simulation of land-use and land-cover change: a review Ann. Assoc. Am. Geogr. 2003, 93 (2) 314337

15. Vespignani, A.Modelling dynamical processes in complex socio-technical systems Nat. Phys. 2012, 8 ( 1) $32-39$

16. O'Sullivan, D.; Haklay, M.Agent-based models and individualism: is the world agent-based? Environ. Plan. A 2000, 32 ( 8) 1409-1425

17. Bedan, E. S.; Clausen, J. C.Stormwater runoff quality and quantity from traditional and low impact development watersheds(1) J. Am. Water Resour. Assoc. 2009, 45 ( 4) 998-1008

18. Montalto, F.; Behr, C.; Alfredo, K.; Wolf, M.; Arye, M.; Walsh, M.Rapid assessment of the costeffectiveness of low impact development for CSO control Landsc. Urban Plan. 2007, 82 ( 3) 117- 131

19. Pyke, C.; Warren, M. P.; Johnson, T.; LaGro, J.; Scharfenberg, J.; Groth, P.; Freed, R.; Schroeer, W.; Main, E.Assessment of low impact development for managing stormwater with changing precipitation due to climate change Landsc. Urban Plan. 2011, 103 (2) 166-173

20. Angrill, S.; Farreny, R.; Gasol, C. M.; Gabarrell, X.; Vinolas, B.; Josa, A.; Rieradevall, J.Environmental analysis of rainwater harvesting infrastructures in diffuse and compact urban models of Mediterranean climate Int. J. Life Cycle Assess. 2011, 17 ( 1) 25-42

21. Williams, E. S.; Wise, W. R.Economic impacts of alternative approaches to storm-water management and land development J. Water Resour. Planning Manage.-ASCE 2009, 135 ( 6) 537- 546

22. Gearheart, G. A review of low impact development policies: removing institutional barriers to adoption; California State Water Resources Control Board Stormwater Program, and The Water Board Academy:

2007.http://www.opc.ca.gov/webmaster/ftp/pdf/agenda_items/20080229/06_LID/0802COPC_06_Ex\% 202\%20CA_LID_Policy_Review_Final.pdf (accessed July 10, 2013).

23. Roy, A. H.; Wenger, S. J.; Fletcher, T. D.; Walsh, C. J.; Ladson, A. R.; Shuster, W. D.; Thurston, H. W.; Brown, R. R.Impediments and solutions to sustainable, watershed-scale urban stormwater management: Lessons from Australia and the United States Environ. Manage. 2008, 42 ( 2) 344- 359

24. Xu, M.; Weissburg, M.; Newell, J. P.; Crittenden, J. C.Developing a science of infrastructure ecology for sustainable urban systems Environ. Sci. Technol. 2012, 46 ( 15) 7928- 7929

25. March, J. G.Bounded rationality, ambiguity, and engineering of choice Bell J. Econ. 1978, 9 ( 2) 587608 
26. Todeschini, S.; Papiri, S.; Ciaponi, C.Performance of stormwater detention tanks for urban drainage systems in northern Italy J. Environ. Manage. 2012, 101, 33- 45

27. Filatova, T.; Parker, D.; Veen, A.Agent-based urban land markets: agent's pricing behavior, land prices and urban land use change J. Artif. Soc. Soc. Simul. 2009, 12 (1) 29

28. Magliocca, N.; Safirova, E.; McConnell, V.; Walls, M.An economic agent-based model of coupled housing and land markets (CHALMS) Comput. Environ. Urban Syst. 2011, 35 ( 3) 183-191

29. Bowman, T.; Tyndall, J. C.; Thompson, J.; Kliebenstein, J.; Colletti, J. P.Multiple approaches to valuation of conservation design and low-impact development features in residential subdivisions J. Environ. Manage. 2012, 104, 101-113

30. Bowman, T.; Thompson, J.; Colletti, J.Valuation of open space and conservation features in residential subdivisions J. Environ. Manage. 2009, 90 ( 1) 321- 330

31. Peiser, R. B.; Schwann, G. M.The private value of public open space within subdivisions J. Archit. Plan. Res. 1993, 10 ( 2) 91- 104

32. Ligmann-Zielinska, A.; Sun, L. B.Applying time-dependent variance-based global sensitivity analysis to represent the dynamics of an agent-based model of land use change Int. J. Geogr. Inf. Sci. 2010, 24 ( 12) 1829- 1850

33. Grimm, V.; Revilla, E.; Berger, U.; Jeltsch, F.; Mooij, W. M.; Railsback, S. F.; Thulke, H. H.; Weiner, J.; Wiegand, T.; DeAngelis, D. L.Pattern-oriented modeling of agent-based complex systems: Lessons from ecology Science 2005, 310 ( 5750) 987-991

34. McConnell, V.; Walls, M. The value of open space: evidence from studies of nonmarket benefits; Resouce of the Future: 2005. http://www.rff.org/rff/Documents/RFF-REPORT-Open\%20Spaces.pdf (accessed July 10, 2013).

35. Ward, B.; MacMullan, E.; Reich, S.The effect of low-impact-development on property values Proceedings of the Water Environment Federation, Sustainability 2008, 318-323

36. Francis, M.Village homes: a case study in community design Landscape J. 2002, 21 (1) 23-41

37. Green infrastructure for Los Angeles: addressing urban runoff and water supply through low impact development; City of Los Angeles, 2009. http://www.environmentla.org/pdf/LID-Paper_4-109_530pm.pdf (accessed July 10, 2013).

38. Schmitz, N. J. Open space in residential subdivisions: effect of low impact development and open space on single-family housing values. M.A. thesis, University of Nebraska, Omaha, NE, 2008.

39. Burge, G.; Ihlanfeldt, K.Impact fees and single-family home construction J. Urban Econ. 2006, 60 ( 2) 284- 306 
40. Trantopoulos, K.; Schlapfer, M.; Helbing, D.Toward sustainability of complex urban systems through techno-social reality mining Environ. Sci. Technol. 2011, 45 ( 15) 6231-6232

41. Russell, M. A. Mining the social web; O’Reilly Media, Inc.: Sebastopol, U.S., 2011.

42. Gonzalez, M. C.; Hidalgo, C. A.; Barabasi, A. L.Understanding individual human mobility patterns Nature 2008, 453 ( 7196) 779- 782

43. Malleson, N.; Birkin, M.Analysis of crime patterns through the integration of an agent-based model and a population microsimulation Comput. Environ. Urban Syst. 2012, 36 ( 6) 551- 561 